and hydrogen evolved exactly proportional to the current passing. If a silver voltameter were included in the circuit, for every milligramme-equivalent (108 milligrammes) of silver deposited, I milligramme-cquivalent of hydrogen occupying II' 2 cubic centimetres and 8 milligrammes of oxygen occupying $5^{\circ} 6$ cubic centimetres at $0^{\circ} \mathrm{C}$. and 760 millimetres, were liberated.

Although Sir William Thomson did not publish"any electrical theoretical work in 1887 , he perfected during that year his practical electrical measuring instruments. They are in use at the Grosvenor Gallery central station in London. There are no more beautiful or accurate instruments in the world, and they reach over an enormous range both of potential and of current measurement. They were admirably illustrated and described in Industries of January 27 by Prof. Fleming.

Hertz (Wiedemann Ann. I887), has shown that the ultraviolet rays have an influence on the passage of sparks. E. Wiedeman and $\mathrm{H}$. Ebert have been repeating and verifying his experiments. The effect of light falling on the spark region was to lower the potential required to produce it. If a succession of sparks be sent, and a telephone be used, the effect of light falling on the sparks was to change not only the note but the whole character of the sound heard in the telephone. If a Geissler's tube were used, an intermittent and irregular dis. charge became steady and continuous. The effect was evident only on the negative pole.

IT is known that the magnetic qualities of iron diminish considerably when raised to $525^{\circ} \mathrm{C}$. (red heat), but iron remains magnetic up to $650^{\circ} \mathrm{C}$. Nickel loses its magnetic properties suddenly at $3 \mathrm{CO}^{\circ} \mathrm{C}$. Lodeboer recently (January 9) read a paper before the Académie des Sciences, in which he showed that with magnetizing forces of 35 , roo, and 200 C.G.S. units the iron retains its magnetic properties up to $680^{\circ} \mathrm{C}$. ; that beyond this temperature it rapidly loses them; that at $750^{\circ} \mathrm{C}$. they scarcely exist, and at $770^{\circ} \mathrm{C}$. they entirely disappear, to reappear only on cooling. It is known that the specific heat of iron undergoes a change of condition between $660^{\circ}$ and $720^{\circ} \mathrm{C}$., and the coincidence of these two changes is very interesting.

THE treatment of sewage by electricity is, it seems, likely to receive a practical test at the Metropolitan Board of Works' outfall at Crossness. Mr. Fewson, of Buckingham, made some experiments in this direction at Wimbledon last summer, and now Mr. W. Webster is about to do the same thing at one of the large tanks on the Thames. The electric current is said to have a wonderful disinfecting and purifying infuence. The evolution of gas stirs up the liquid, the nascent oxygen is brought into rapid contact with the impurities and reduces them, precipitation is expedited, and the whole cleansed. It is to be hoped that the cost will not swamp this new and useful field for electricity.

THE extraordinary rise in the price of copper has attracted much attention to the use of iron for lightning conductors. Prof. Silvanus Thompson advocates iron in preference to copper under all circumstances. Iron is much used by the War Department to protect magazines. Dr. L. Weber recommends it even in a solid form rather than as a stranded rope, but the latter form is much more portable and workable; moreover, Prof. Hughes showed it to be less subject to self-induction than a solid rodan obstruction not to be neglected. Iron conductors are stronger, much cheaper, less easily fused, and less liable to theft than copper. There can be no objection to the use of iron.

THE electro-deposition of aluminium has attracted much attention since the introduction of the Cowles process. Herman Reinbold has proposed the following solution, with which he has obtained good but small results : alum 50 parts, water 300 parts, aluminium chloride ro parts. This solution is heated to $200^{\circ} \mathrm{F}$, and after cooling 39 parts of potassic chloride are added.

\section{THE INSTITUTION OF MECHANICAL} ENGINEERS.

THIS Society held its forty-first annual general meeting in the theatre of the Institution of Civil Engineers on Thursday and Friday of last week. After the Annual Report had been presented and accepted, Mr. John Richards' pape "On Irrigating Machinery on the Pacific Coast" was read and discussed. The need of irrigation in this district arises from three causes: the lack of rain, which ceases altogether along the coast in summer-time; the want of surface-water; and the free percolation into the sandy soil beneath. The whole of the land in the country, excepting the low-lying sedimentary plains near the mouths of the rivers, and around the Bay of San Francisco, where water reaches the surface by capillary saturation, requires irrigation. Nearly all the land upon which water can be led, either by training small mountain streams, or by leading long canals from the rivers, has been occupied, so that the only remaining resource for getting water will be by lifting it from the rivers or the gravel strata by machinery. The paper is descriptive of the various pumps and hydraulic rams employed, and was illustrated by means of thirty-five figures.

Mr. William Geipel's paper "On the Position and Prospects of Electricity as applied to Engineering " refers to those branches of electric engineering which involve the employment of con siderable power, and are in some way or other connected with the use of dynamos. They comprise electric transmission and distribution of power, and electric lighting, loccmotion, and metallurgy.

In the author's opinion the transmission and distribution of power by electricity will occupy in the near future most of the attention of the electric engineer. Owing to its simplicity, the ease with which an electric motor can be applied to any purpose requiring power, and its high efficiency, it is certainly an approach to an ideally perfect system of transmission. In the United States great strides have been made in the applications of electric motors, which already rival those for lighting purposes. One of the great advantages of these applications is due to the low efficiency of belts and shafting where high speed is required and the demand for power is variable. By getting rid of shafting the necessity for additional stability in buildings is obviated, and constant lubrication is done away with. The distribution of power by elec: ricity from a central station to small users can be effected from the same mains and generators as are used for electric light purposes; as to whether gas through the medium of gas engines or electricity by means of electric motors should be used, will become entirely a question of economy and con venience. On the one hand the electric motur can be started and stopped with the greatest ease, it requires little attention, occupic s little space, and can be placed anywhere, while against the use of the gas engine, the author brings forward its irregularity of speed owing to the intermittent impulse and the wear and tear in the valves and working parts. Shunt motors, which are now almost exclusively used, possess a practically perfect power of self-control, not only over their rate of speed with varying load, but over the energy absorbed, for they help themselves, as it were, to only such an amount of energy as will enable them to deal with the work imposed upon them. Another advantage in shunt motors, first pointed out by the late Sir William Siemens in $\mathbf{1} 880$, is that they act as generators when themselves driven by any extraneous power, without any complication of the switch gear required with series motors. The author refers to various installations which have already taken place in Europe and America, which are paying their way, whilst at the Falls of Niagara plant is being put down to distribute power obtained from the Falls to neighbouring towns, including Buffalo, which is twenty miles distant; the amount of power is stated at 15,000 h.p., of which 10,000 h.p. is contracted for at $£ 3$ per h.p.

Electricity has been applied with efficiency in collieries for underground hauling, pumping, ventilating, and drilling; in ship-yards and similar works it has been proved to be a suitable and economical means of transmitting power for riveting, drilling, \&c.

In its application to the transmission of power to great distances, electricity is found to be more economical than either hydraulic, pneumatic, or wire-rope transmission, and comparative tables are given showing the first cost of plant per horse-power transmitted, and also the working cost per horse-power transmitted per hour. For a distance of 22,000 yards the cost of installation for the transmission of 100 b.p. is $£ 87, £ 310, \notin 192$, and $£$ I62 per h.p. for electric, hydraulic, pneumatic, and wire-rope transmission respectively; whilst the cost per h.p. transmitted per hour is $4^{\circ} 8.6 .84,4^{\circ} 5^{\circ}$, and 9.73 pence.

Amongst many interesting applications, that made by the Marquis of Salisbury at Hatfield may be specially referred to. The River Lea is utilized to generate electricity by means of turbines, the electricity being transmitted to the house and over the estate for a variety of purposes. The moters at the house 
drive pumping and ice-making machinery and an air-propeller fixed in the roof for ventilating ; on the farm the motors are used for elevating hay and corn sheaves to the top of the stacks, for thrashing, for cutting rough grass with a chaff-cutting machine for ensilage, in fields extending to a distance of two miles, for grinding corn, \&c., to make fodder, and for other purposes. The motors have also been used for pile-driving, for making cofferdams where necessary in the river, and also for dredging the river and clearing it of weeds, and for pumping the town sewage into a tank at the height of thirty feet for irrigation. The conductors are carried overhead on poles about the farm and underground in wonden troughs to the house. The practical methods employed for electric locomotion-being those of a third insulated rail, an overhead conductor, an underground insulated conductor, and storage batteries-are described, and examples of the application of all are given. To the first belong the Portrush Railway, and Besbrook and Newry Tramway; to the next the electric railway at Moedling, near Vienna, and the Frankfort-Offenbach railway. This plan has been most largely adopted in America, where there are probably not far short of one hundred electric railways at work and projected. Of the underground conductor, the most important example is the electric tramway at Blackpool, while storage batteries are being employed on the North Metropolitan Tramway in London. The ordinary rails have been used as conductors in the short electric railway at Brighton, where the expenses amount to twopence per car-mile.

The plan of transporting material in skips on overhead wire. ropes by means of electricity, introduced under the name of telpherage by Prof. Fleeming Jenkin, has been employed wit! success for two years past at Glynde, near Lewes, for.transporting clay to the railway over a distance of 1600 yards, and is applicable for use in places where material has to be conveyed across hilly districts. In the author's opinion a modification of this plan might be advantageously applied to alleviate the heavy street traffic in our larger cities.

The author considers the question of electric lighting under the three aspects of comfort, convenience, and economy. As regards the first two, electric lighting has the advantage over other systems ; whilst as regards cost, although electric lighting, and especially incandescent electric lighting, is still heavy, yet for lighting main streets and railway stations, or other places where concentrated light is required, the arc light is cheaper than gas. As its use extends, the cost of working becomes reduced. Thus in the Waverley Station, Edinburgh, on the North British Railway, thirty-three arc lamps, with 4I,884 lamp hours, cost 2.77 pence per lamp hour from July to December 1884 ; whilst in 1886, thirty-nine arc lamps, having 55,068 lamp hours, cost I '79 penny per lamp hour.

The cost of incandescent lighting is especially variable, and affected by the local conditions of the installation. The chief of these are the average number of hours of lighting each lamp, and the average distance of the lamps from the generating station. Where conditions are favourable, incandescent lighting can already compete with gas. Messrs. George Jager and Sons' yearly cost of lighting their sugar refinery at Leith is given as an example, it having been $£ 347$ with gas and $£ 204$ with in candescent lamps. The author draws special attention to the circumstance of the much larger application of electricity to lighting in the United States as compared with this country. In the United States there is hardly a city or town of 20,000 in habitants which has not a central station for arc or incandescent lamps; and many towns of 3000 to 4000 inhabitants are also supporting them.

The efficiency of dynamo machines being as high as 95 per cent., and there not being much likelihood of material improvement in steam engines, the author draws attention to the importance of improving the lamps by making them with a higher resistance and greater efficiency, the voltage having a great effect on the cost of working distant lamps. Transformers, by means of which high tension currents of electricity, sent from a distant generating station along a small conductor with comparatively small percentage of loss, can then be converted into low tension currents for the supply of ordinary incandescent lamps, are receiving a large amount of attention, the loss by conversion being as low sometimes as 5 per cent. Efforts are also being made to introduce the system of secondary batteries, charged in series by a high tension current, and discharged in parallel circuit, and if it can once be demonstrated to be economical, there would be a large field of application. At Leamington an extensive central station is now at work, the

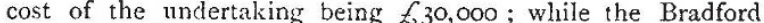
Corporation have recently voted a sum of $£ 15,000$ for erecting a central station in their town. Both these are instances of direct supply without transformers or secondary batteries. Electric metallurgy is a branch of electric engineering to which attention was first drawn by the late Sir William Siemens, whose death occurred before he had perfected his invention. The electrochemical separation of ores on a commercial scale by the electric furnace has been recently put to the test, chiefly in o'taining aluminium from conundrum. The furnace designed by Prof. Mabery is built of fire-brick and lined with powdered charcoal; electricity is conducted to the ore by carbon rods, meeting near the centre. The ore mixed with charcoal and granulated copper surrounds and covers the carbons; the furnace is closed with a layer of charcoal and a lid lined with fire-brick. A current of 50 volts electromotive force is supplied and melts the metal around the electrodes, which are moved apart gradually until the whole is melted. The conundrum becomes gradually deoxidized, the aluminium combining with the copper, while the oxygen with the carbon escapes as carbonic oxide, about five hours sufficing to complete the reduction. Aluminium, being only one-third the weight of iron, and possessing great strength, its production at a cheap rate would probably cause a revolution in engineering construction.

The meeting was presided over by Mr. E. H. Carbutt, the President, who was re-elected to the chair, whilst Sir Douglas Galton, K.C.B., was the new member elected on the Council. The meeting was as usual of a very successful character.

\section{THE NATIONAL S.MOKE ABATEMENT} INSTITUTION. ${ }^{1}$

$\mathrm{N}$ presenting the Report to the members for the year 1887 , the Council consider it desirable to reprint from the Memorandum of Association the objects for which the Institution was established. These are the following :-

To promote the abatement of coal smoke and other noxious products of combustion in cities and other places, in order to render the atmosphere as pure and as pervious to sunlight as practicable. To check the present serious waste of coal, and the direct and indirect loss and damage accompanying the overproduction of smoke and noxious products of combustion. To continue, organize, and extend the public movement inaugurated and hitherto carried on by the Smoke Abatement Committees (otherwise known as the Joint Committees for Abatement of Smoke, appointed by the National Health Society and Kyrle Society of London, and the Smoke Abatement Committee of Mancoester), and to take up and proceed with any work undertaken or commenced by such Committees. To advance the aforesaid objects by promoting and enc uraging the better and more economical use of coal and coal protucts, and the selection of suitable fuel, as well as general improvement in the various modes of obtaining, applying, and using heat and light for domestic and industrial purposes. And in connection with such objects to obtain and provide such buildings, appliances, and assistance as may be deemed expedient. And without prejudice to the advancement of the objects aforesaid by other means to advance the same by the following means more particularly :-

(a) By calling public attention to the serious pecuniary loss and injury, to the health and comfort, which arise from coal smoke, and from defective heating, ventilating, and lighting arrangements.

(b) By stimulating, assisting, and encouraging inventors, manufacturers, traders, and others to bring forward, develop, and perfect new or improved fuels, substances, methods, and appliances for the generation or application of heat or light and for consuming or lessening the production of smoke and noxious products of combustion.

(c) By conducting practical trials of fuels, apparatus, ancl systems connected with the generation or application of heat or light, and causing reports to be made thereon for the guidance, assistance, or information of inventors, traders, intending users, and the public generally.

(d) By granting awards, certificates, medals, or prizes in connection with approved fuels, methods, or apparatus.

(e) By establishing, or assisting in establishing, public ex hibitions, either periodical or otherwise, of appliances pertaining to heating, ventilating, or lighting.

${ }^{I}$ Report of the Council for the year 1887 . 